\title{
Examining tourism management students' cognitive structure towards cittaslow-slow city through word association test
}

Erhan Coşkun ${ }^{1}$, Seden Doğan ${ }^{2}$

\begin{abstract}
The purpose of the research is to reveal the cognitive structures of the associate degree students about the concepts related to the slow city concept through the Word Association Test (WAT), which is an alternative measurement evaluation technique. For this purpose, 58 associate degree students were applied WAT. The concept of slow city key was given to students and they were asked to write the words that the key concept brought to their mind in a certain period of time. The data obtained were recorded in a frequency table. The data in this frequency table and the 16-dimensional concept map showing the cognitive structure of students were drawn. In addition, the relevant sentences to be established for the key concept were analyzed by their classification according to their meaning and characteristics. The results have been aimed to reveal the subjects that students who are at associate degree in the tourism management program are lacking in the concept of slow city. So, suggestions towards vocational schools involving this program have been presented.
\end{abstract}

Keywords: Slow City, Word Association Test, Tourism Education.

Turizm işletmeciliği öğrencilerinin cittaslow - yavaş şehir kavramına yönelik bilişsel yapılarının kelime ilişkilendirme testi aracılığıyla incelenmesi

$\ddot{\theta_{z}}$

Araştırmanın amacı alternatif bir ölçme değerlendirme tekniği olan Kelime İlişkilendirme Testi (KİT) aracılı̆̆ıyla turizm işletmeciliği programında öğrenim gören ön lisans öğrencilerinin yavaşs şehir kavramı ile ilişkili kavramlar hakkında bilişsel yapılarını ortaya koymaktır. Bu amaçla 58 ön lisans öğrencisine KİT uygulanmıştır. Öğrencilere yavaşşehir anahtar kavramı verilmiş ve belli bir süre içinde bu anahtar kavramın akıllarına getirdiği kelimeleri yazmaları istenmiştir. Elde edilen veriler, bir frekans tablosuna kaydedilmiştir. Bu frekans tablosundaki veriler ile öğrencilerin bilişsel yapısın ortaya koyan 16 boyutlu kavram haritası çizilmiştir. Ayrıca anahtar kavrama yönelik olarak kuracakları ilgili cümleler, içerdikleri anlam ve sahip oldukları özelliklere göre sınıflandırılarak analiz edilmiştir. Elde edilen sonuçların, turizm işletmeciliği programında ön lisans eğitimi gören öğrencilerin yavaş şehir kavramıyla ilgili eksik oldukları konuları ortaya koyması hedeflenmiştir. Bu sayede bu programın olduğu meslek yüksekokullarına yönelik öneriler sunulmuştur.

Anahtar sözcükler: Yavaş Şehir, Kelime İlişkilendirme Testi, Turizm İşletmeciliği Eğitimi

$\begin{array}{ll}\text { Geliş Tarihi } & : 27.09 .2018 \\ \text { Kabul Tarihi } & : 01.03 .2019\end{array}$

Alıntı için: Coşkun, E., Doğan, S. (2019). Turizm işletmeciliği öğrencilerinin cittaslow - yavaş şehir kavramına yönelik bilişsel yapılarının kelime ilişkilendirme testi aracılığılla incelenmesi Journal of Tourism Theory and Research, 5(2), 273-281.

${ }^{1}$ erhancoskun@adu.edu.tr

${ }^{2}$ seden.dogan@omu.edu.tr 


\section{Giriș}

Boş zamanın ve gelir düzeyinin artmasına bağlı olarak turizm hareketine katılanların sayısı sürekli artış göstermektedir. Birleşmiş Milletler Dünya Turizm Örgütü (UNWTO)'ne göre uluslararası turist varışları 2017 y1lında $\% 7$ oranında bir büyüme kaydederek toplamda 1,3 milyara ulaşmıştır. Öte yandan dünyadaki eğilimler, bireylerin eğitim ve refah düzeyindeki yükselmenin artarak devam edeceğini ve turizmde deneyimli gezginlerin sayısının artacağını göstermektedir. Seyahat edenlerin yenilik ve çeşitlilik talebi artmaya devam edecektir. Klasik turizm anlayışı, yerini yeni turizm türlerine bırakmış durumdadır. Bu bağlamda tüketim odaklı hayatın insanlara mutluluk ve huzur getirmediğinden hareketle, farklı yaşam biçimi arayışları sonucunda 1999 'da İtalya'da başlayan cittaslow - yavaş şehir hareketi, insanların birbirleriyle iletişim kurabilecekleri, sosyalleşebilecekleri, kendine yeten, sürdürülebilir, el sanatlarına, doğasına, gelenek ve göreneklerine sahip çıan, alt yapı sorunları olmayan, yenilebilir enerji kaynakları kullanan, teknolojinin kolaylıklarından yararlanan kentlerin oluşmasını hedeflemektedir.

Bu noktada turizm işletmeciliği eğitimi alan üniversite öğrencilerinin cittaslow - yavaş şehir kavramına yönelik k bilişsel yapılarını ortaya çıkararak cittaslow - yavaş şehir konusundaki bilgi belirlemeyi amaçlayan bu araştırma, Adnan Menderes Üniversitesi Davutlar Meslek Yüksekokulu Turizm ve Otel İşletmeciliği program 12 . sınıfinda öğrenim gören 58 öğrenci ile gerçekleştirilmiştir. Araştırmada Kelime İlişkilendirme Testi kullanılmış olup öğrencilerin cittaslow - yavaş şehir anahtar kavramına karşılık olarak verdikleri yanıtlar kullanılarak 16 boyutlu kavram haritası oluşturulmuştur.

\section{Literatür}

\subsection{Cittaslow-yavaş şehir}

21. yy'ın kalabalık, büyük ve gürültülü kentlerine alternatif olan Yavaş Şehir, İtalyanca Citta (Kent) ve İngilizce Slow (Yavaş) kelimelerinin birleşiminden oluşmaktadır (Acuner, 2014:1). Cittaslow - Yavaş Şehir, 1999 yllinda Paolo Saturnini (Greve in Chianti Belediye Başkanı) tarafından Orvieto (Stefano Cimicchi), Bra (Francesca Guida), Positano (Domenico Marrone) şehirlerinin belediye başkanları ve Carlo Petrini (Slow
Food Başkanı) ile birlikte kurulmuştur (Radstrom, 2011:91).

Cittaslow - Yavaş Şehir, nüfusu 50.000'den az olan ve kendine has çevresel, arkeolojik ya da kültürel değerleri olan şehirleri bir araya getirmektedir (Zawadzka, 2017:94). Uluslararası küçük şehirlerden oluşan bir ağ olan Cittaslow - Yavaş Şehir, iyi, temiz ve adil gida ilkelerine sahip slow food (yavaş yemek) felsefesinin (Slow Food, 2018) kentsel tasarım ve planlamaya uyarlanması amaciyla İtalya'da kurulmuştur (Yurtseven ve Kaya, 2011:91). İnsanlara teknolojiyi kullanarak daha sağlıklı ortamlar yaratmak, yavaş yaşamın değeri hakkında farkındalık kazandırmak ve daha kaliteli yaşama yönelik idari çözümler bulmayı taahhüt etmektedir (Knox, 2007:7).

Bugün dünya genelinde 30 ülkede 252 Yavaş Șehir bulunmaktadır. Bu 252 şehrin 84'üne sahip olan İtalya bu anlamda ilk sırada yer alırken 15 Yavaş Şehir'e sahip Türkiye ise 4. sırada yer almaktadır (Cittaslow, 2018). Cittaslow - Yavaş Şehir hareketi slow food kavramına dayanırken, şehirlere ve turizm alanına da uzanarak daha da geliştirilmektedir. Son yıllarda, slow travel (yavaş seyahat) kavramı da Cittaslow - Yavaş Şehir ile ilgili bir kavram haline gelmiştir (Su, vd., 2017:92).

\subsection{Kelime ilișkilendirme testi}

Araştırmada öğrencilerin Yavaş Şehir kavramına ilişskin bilişsel yapılarını belirlemek amacıyla veri toplama aracı olarak kelime ilişkilendirme testi kullanılmıştır. Kelime İlişkilendirme Testi (KİT), öğrencilerin bilişsel yapısındaki kavramlar arasındaki bağlantıları ortaya çıarmaktadır ve uzun süreli bellekteki kavramlar arasındaki ilişkinin yeterli veya anlamlı olup olmadığını belirlemektedir. Bu teknikte öğrencilerden 30 ila 45 saniye içinde anahtar kavramın zihinlerinde çağrıştırdığı sözcükleri yazmaları istenmektedir. Kelime İlişkilendirme Testi; öğrencilerin sadece bilgi seviyesini ölçmekle kalmayıp aynı zamanda zihinsel yapıları arasındaki ilişkiyi de ortaya koymaktadır. Öğrenci zihnindeki bilgiler arasındaki ilişkiyi, yeni bilgi ağını ve önceki bilgiler ile yeni bilginin arasındaki ilişkinin anlamlı olup olmadığını ortaya çıkarmada en yaygın kullanılan tekniklerden biridir (Altıntaş vd., 2018:1403; Başar ve Göncü, 2018:189; Gündoğan ve Gültekin, 2018:236; Doğan vd., 2018:169; Yücel Güngör vd., 2017:210; Önal, 2017:257; Önel ve Yüce, 2016:26; 
Keleş vd., 2016:6; Keskin ve Örgün, 2015:32; Ekici vd., 2014:362). Son y1llarda sosyal alanlarda özellikle eğitim bilimlerinde kullanılan Kelime İlişkilendirme Testi, turizm alanındaki akademik araştırmalarda da kullanılmaktadır (Doğan vd., 2018; Yücel Güngör vd ., 2017; Kesin vd., 2017; Keskin ve Örgün, 2015).

\section{Yöntem}

\subsection{Araştırmanın amact}

Araştırmanın amacı alternatif bir ölçme değerlendirme tekniği olan Kelime İlişkilendirme Testi (KİT) aracılığıyla turizm işletmeciliği programında öğrenim gören ön lisans öğrencilerinin yavaş şehir kavramı ile ilişkili kavramlar hakkında bilişsel yapılarını ortaya koymaktır.

\section{2. Örneklem ve veri toplama}

Zaman kısıtı nedeniyle araştırmada Tesadüfi Olmayan Örnekleme yöntemlerinden Kolayda Örnekleme tercih edilmiştir. Kolayda örnekleme, ana kütle içerisinden seçilecek örnek kesimin araştırmacının yargılarınca belirlendiği tesadüfî olmayan örnekleme yöntemidir. Kolayda örneklemede veriler, ana kütleden en kolay, hızlı ve ekonomik şekilde toplanmaktadır (Çeliköz ve Erişen, 2017:289, Firat ve Aydın, 2016:1843; Gülertekin Genç vd, 2016:105). Bu doğrultuda çalışma grubu olarak Adnan Menderes Üniversitesi Davutlar Meslek Yüksekokulu Turizm İşletmeciliği Programı 2. sınıfında öğrenim gören 60 öğrenci olarak belirlenmiştir. Verilerin toplanması için belirlenen tarihte derste bulunan 58 öğrenci ile araştırma gerçekleştirilmiştir.

Veri toplama aracı olarak kelime ilişkilendirme testi kullanılmıştır. Araştırmada "Yavaş Şehir" kavramı bir sayfada $10 \mathrm{kez}$ alt alta sıralanmıștır. Alt alta $10 \mathrm{kez}$ yazılmasının nedeni zincirleme cevap riskini önlemektir. Çünkü öğrenci, her kavram yazımında anahtar kavram yerine cevap olarak yazdığ 1 kavramın aklına getirdiği kelimeleri yazabilmekte, bu da testin amacına ulaşmasına engel olabilmektedir. Uygulama öncesinde öğrencilere kelime ilişkilendirme testine yönelik açıklamalar yapılmış ve testin uygulanması esnasinda öğrencilerden 60 saniye içerisinde anahtar kavramın akıllarına getirdiği ilgili kavramları yazmaları istenmiştir. Ayrıca ilgili cümle kısmı tek bir cevap kelimesine göre daha karmaşık ve üst düzey yapıda olacağından cümlenin bilimsel olup olmaması, farklı nitelikte kavram yanılgıları içerip içermediği gibi durumlar değerlendirme sürecinde önemli rol oynamaktadır.

\subsection{Bulgular}

58 öğrenciye yapılan Kelime İlişkilendirme Testi sonucunda elde edilen veriler Tablo 1'de gösterilmektedir. Buna göre 16 kategori elde edilmiştir. Bu kategorilerin frekans toplamı 413'tür. Kategorilerin altında yer alan alt gruplar 296 kelimeden oluşmaktadır. Tablo 1 'de alt grupların tamamı yerine her kategoriden 5 olmak üzere frekansı en yüksek olan 30 kelimeye yer verilmiştir. Bu kelimelerin frekans toplamı ise 185'tir.

Tablo 1'e bakıldığında frekans değeri en yüksek olan kategorinin destinasyon kişiliği (78) olduğu görülmektedir. Öğrenciler için "Cittaslow - Yavaş Şehir" kavramı sakinlik (13), durgunluk (6), sessizlik (5), s1kıcı (3) ve bıkkınlık (2) kelimeleriyle açıklanırken anahtar kavramın destinasyona yönelik kişilik özelliklerinin öğrencilerde olumlu ve olumsuz çağrışımlarda bulunduğu tespit edilmiştir.

İkinci kategoride ise anahtar kavramın ekonomi ile ilişkilendirildiği görülmektedir. Gelişmemiş (22), gelişmeye çalışan (8), düşük ekonomi (5), geri kalmış (4) ve ekonomi (2) kelimeleriyle ilişkilendirme yapılmıştır. Bu durum anahtar kavramın ekonomik anlamda olumsuz bir çağrışım yaptığı tespit edilmiştir.

Üçüncü kategoride anahtar kavram sunulan imkanlar ve imkansızlıklar ile ilişkilendirilmiştir. Eğlence az (4), aksiyon yok, aktivite az, altyapısı zayıf ve belirli saatlerde yaşam var kelime ve kelimeleriyle anahtar kavram ilişkilendirilmiştir. Buna göre anahtar kavramın sunulan imkanlar açısından zayıf olduğu sonucuna ulaşı1mıştır.

Dördüncü kategoride öğrencilerin anahtar kavramı yaşam tarzı ve orada yaşayan insanlar ile açıklamaya çalıştığı belirlenmiştir. Sosyal yaşam az (3), gürültüsüz (2), hayat (2), alış1lagelmiş ve beraberlik kelimelerini kullanan öğrencilere göre anahtar kavramın yaşam tarzı ile ilgili olumlu ve olumsuz ve insanlar ile ilgili olumlu çağrışımlar yaptığ 1 görülmüştür.

Beşinci kategoride anahtar kavram ile insan sayısı ilişkilendirilmiştir. Yaşlı nüfus (9), az nüfus (6), kalabalık (6), az insan (3), emekli çok kelimeleri ile anahtar kavram ilişkilendirilmiştir. Buna göre anahtar kavramın yaşlı ve emekli insan sayısının fazla ve kalabalık olduğu çağnışımını yaparken insan sayısının az olduğu sonucuna da ulaşılmıştır. 
Tablo 1. "Yavaş şehir" anahtar kavrama verilen cevaplar

\begin{tabular}{|c|c|c|c|}
\hline Kategoriler & Alt Gruplar ve Frekanslar & $\begin{array}{l}\text { Frekans } \\
\text { Toplamı }\end{array}$ & $\begin{array}{c}\text { Yüzde } \\
(\%)\end{array}$ \\
\hline \multirow{5}{*}{$\begin{array}{l}\text { 1-Destinas- } \\
\text { yon Kişi- } \\
\text { liği }\end{array}$} & Sakinlik (13) & \multirow[t]{5}{*}{78} & \multirow[t]{5}{*}{18.9} \\
\hline & Durgunluk (6) & & \\
\hline & Sessizlik (5) & & \\
\hline & S1k1c1 (3) & & \\
\hline & B1kkınlık (2) & & \\
\hline \multirow{5}{*}{$\begin{array}{l}\text { 2-Ekono- } \\
\text { mik Durum }\end{array}$} & Gelişmemiş (22) & \multirow[t]{5}{*}{74} & \multirow[t]{5}{*}{17.9} \\
\hline & Gelişmeye çalışan (8) & & \\
\hline & Düşük ekonomi (5) & & \\
\hline & Geri kalmış (4) & & \\
\hline & Ekonomi (2) & & \\
\hline \multirow{5}{*}{$\begin{array}{l}\text { 3-İmkanlar } \\
\text { / Kisitl1 } \\
\text { İmkanlar }\end{array}$} & Eğlence az (4) & \multirow[t]{5}{*}{40} & \multirow[t]{5}{*}{9.7} \\
\hline & Aksiyon yok & & \\
\hline & Aktivite az & & \\
\hline & Altyapısı zayıf & & \\
\hline & Belirli saatlerde yaşam var & & \\
\hline \multirow{5}{*}{$\begin{array}{l}\text { 4-Yaşam } \\
\text { Tarzı Ve } \\
\text { Insanlar }\end{array}$} & Sosyal yaşam az (3) & \multirow[t]{5}{*}{33} & \multirow[t]{5}{*}{8.0} \\
\hline & Gürültüsüz (2) & & \\
\hline & Hayat (2) & & \\
\hline & Alışılagelmiş & & \\
\hline & Beraberlik & & \\
\hline \multirow[t]{5}{*}{ 5-Nüfus } & Yaşlı nüfus (9) & \multirow[t]{5}{*}{32} & \multirow[t]{5}{*}{7.7} \\
\hline & Az nüfus (6) & & \\
\hline & Kalabalık (6) & & \\
\hline & Az insan (3) & & \\
\hline & Emekli çok & & \\
\hline \multirow{5}{*}{$\begin{array}{l}\text { 6-Fiziksel / } \\
\text { Coğrafik } \\
\text { Yap1 }\end{array}$} & Beton y1ğını & \multirow[t]{5}{*}{24} & \multirow[t]{5}{*}{5.8} \\
\hline & Binalar az & & \\
\hline & Boş arsa & & \\
\hline & Doğal yaşam & & \\
\hline & Dağınık yerleşke & & \\
\hline \multirow{5}{*}{$\begin{array}{l}\text { 7-Destinas- } \\
\text { yonun } \\
\text { Özelliği }\end{array}$} & Eğlence & 23 & 5.6 \\
\hline & Emekli şehri & & \\
\hline & Eski şehir & & \\
\hline & Kafa dinleme & & \\
\hline & Keşfedilmemiş & & \\
\hline 8-Diğer & Stop (2) & 23 & 5.6 \\
\hline & Az zaman & & \\
\hline & Balkon & & \\
\hline & Beyin trafiği & & \\
\hline & Bilim kurgu filmi & & \\
\hline 9-Trafik/ & Trafik (13) & 23 & 5.6 \\
\hline Vasita & Arabalar & & \\
\hline & Minibüsler & & \\
\hline & Motorsiklet & & \\
\hline & Zor ulaşım & & \\
\hline 10-Zayıf- & Boş (2) & 18 & 4.4 \\
\hline liklar & Lanetli (2) & & \\
\hline & Beklenti yok & & \\
\hline & Doğanın korunmaması & & \\
\hline & Gereksiz şehir & & \\
\hline 11-Yavaş & Ağır (3) & 16 & 3.9 \\
\hline & Durağan & & \\
\hline & Herkes yavaş & & \\
\hline & Herşeyi yavaş olan & & \\
\hline & Yavaş internet & & \\
\hline
\end{tabular}

\begin{tabular}{|c|c|c|c|}
\hline \multirow{5}{*}{$\begin{array}{l}\text { 12-Yerel } \\
\text { Yönetim }\end{array}$} & Belde (2) & \multirow[t]{5}{*}{8} & \multirow[t]{5}{*}{1.9} \\
\hline & Кӧу (2) & & \\
\hline & \begin{tabular}{|l|} 
Kasaba \\
\end{tabular} & & \\
\hline & \begin{tabular}{|l|} 
Muhtar \\
\end{tabular} & & \\
\hline & \begin{tabular}{|l|} 
Şehir \\
\end{tabular} & & \\
\hline \multirow{5}{*}{$\begin{array}{l}\text { 13-Gida/ } \\
\text { Tarım/ } \\
\text { Hayvanc1- } \\
\text { lik }\end{array}$} & Bira & \multirow[t]{5}{*}{7} & \multirow[t]{5}{*}{1.7} \\
\hline & Çiçek & & \\
\hline & \begin{tabular}{|l|} 
Çiftlik \\
\end{tabular} & & \\
\hline & \begin{tabular}{|l|} 
Hayvanc1lık \\
\end{tabular} & & \\
\hline & Tarla & & \\
\hline \multirow[t]{5}{*}{ 14-Eğitim } & Eğitim az (2) & \multirow[t]{5}{*}{6} & \multirow[t]{5}{*}{1.4} \\
\hline & Eğitim yavaş & & \\
\hline & \begin{tabular}{|l|} 
Okul \\
\end{tabular} & & \\
\hline & Okuma-yazma & & \\
\hline & Sinav & & \\
\hline \multirow{3}{*}{$\begin{array}{l}\text { 15-Kültür } \\
\text { Ve Turizm }\end{array}$} & Turizm yok (3) & \multirow[t]{3}{*}{5} & \multirow[t]{3}{*}{1.2} \\
\hline & Kültür farkl1lı̆̆ 1 & & \\
\hline & \begin{tabular}{|l|} 
Turist yok \\
\end{tabular} & & \\
\hline $\begin{array}{l}\text { 16-Sakin } \\
\text { Şehir }\end{array}$ & Sakin şehir (3) & 3 & 0.7 \\
\hline Toplam & $296(185)$ & 413 & 100 \\
\hline
\end{tabular}

Altıncı kategoride öğrenciler anahtar kavramı fiziksel ve coğrafik yapı açısından değerlendirmiştir. Beton yığını, binalar az, boş arsa, doğal yaşam ve dağınık yerleşke kelimelerini kullanarak anahtar kavramı yanitlayan öğrencilerin bu yanıtlarına göre anahtar kavramın yerleşim ve betonarme yapılar açısından hem olumlu hem de olumsuz, doğal yaşam açısından ise olumlu çağrışım yaptığı görülmektedir.

Yedinci kategoride eğlence, emekli şehri, eski şehir, kafa dinleme ve keşfedilmemiş kelimeleri anahtar kavram ile ilişkilendirilmiştir. Buna göre anahtar kavramın bir destinasyona yönelik olumlu özelliklere sahip olduğu sonucuna ulaşılmıştır.

Sekizinci kategoride birbirinden bağımsız kelimeler anahtar kavramla ilișkilendirilmiștir. Anahtar kavramın, stop (2), az zaman, balkon, beyin, trafiği ve bilim kurgu filmi kelimelerini kullanan öğrencilere birbirinden bağımsız ve farklı çağrışımlar da yaptığı kanısına varılmıştır.

Dokuzuncu kategoride anahtar kavram ulaşım ve kullanılan vasıtalar ile ilişkilendirilmiştir. Trafik (13), arabalar, minibüsler, motorsiklet ve zor ulaşım kelimeleri ile anahtar kavram ilişkilendirilmiştir. Buna göre anahtar kavramın ulaşım ve trafik yoğunluğu ile ilgili olumsuz yaptığı kullanılan vasıtaların türü ile ilgili de çağrışım yaptığı tespit edilmiştir. 
Onuncu kategoride anahtar kavramın zayıf yönleri ile ilişkilendirme yapılmıştır. Boş (2), lanetli (2), beklenti yok, doğanın korunmaması ve gereksiz şehir kelimeleri kullanılarak anahtar kavramın zayıf yönleri olan, gereksiz hatta lanetli olduğu şeklinde çağrışım yaptığı öğrenciler tarafından dile getirilmiştir.

Onbirinci kategoride anahtar kavram yavaş kelimesi ile ilişkilendirilmiştir. Ağır (3), durağan, herkes yavaş, her şeyi yavaş olan, yavaş internet kelimeleri kullanılarak anahtar kavramın içinde yer alan slow (yavaş) kelimesinin öğrencilere her şeyin yavaş olduğu çağrışımını yaptığı görülmektedir.

Onikinci kategoride anahtar kavramın yerleşim birimi ve yerel yönetimle ilişkilendirildiği ve belde (2), köy (2), kasaba, şehir ve muhtar kelimeleri kullanılarak anahtar kavramın yerleşim birimlerini ve yöneticilerini çağrıştırdığ 1 tespit edilmiştir.

Onüçüncü kategoride bira, çiçek, çiftlik, hayvancılik ve tarla kelimeleri kullanılarak anahtar kavramın gıda, tarım ve hayvancılıkla ilişkilendirilmeye çalışıdığı görülmektedir. Buna göre anahtar kavramın çiftçilik, hayvancılık, doğa ile ilgili çağrışım yaptığı sonucuna ulaşılmaktadır.
Ondördüncü kategoride anahtar kavram eğitim ile ilişkilendirilmiştir. Eğitim az (2), eğitim yavaş, okul, okuma-yazma ve sinav kelimeleri ile anahtar kavram ilişkilendirilmiştir. Buna göre anahtar kavramın öğrencilerde eğitimle ilgili olumlu ve olumsuz çağrışımlar yaptığ 1 tespit edilmiştir.

Onbeşinci kategoride anahtar kavramın kültür ve turizmle ilişkilendirildiği görülmektedir. Turizm yok (3), kültür farklılığ 1 , turist yok kelimeleri kullanılarak turizmin kötü durumda olduğu ve kültürel farklılıkların olduğu ile ilgili çağrışım yaptığı belirlenmiştir.

Onaltıncı kategoriye bakıldığında frekans değeri en düşük olan kategorinin sakin şehir (3) kategorisi olduğu görülmektedir. Buna göre öğrencilerin daha önce anahtar kavramla ilgili bilgiye sahip olduğu ve anahtar kavramın sakin şehir kavramını çağrıştırdığı sonucuna ulaşı1mıştır.

Aşağıda Şekil 1'de kelime ilişkilendirme testi sonucu oluşturulan kavram haritası yer almaktadır. Şekilde, Tablo 1'de yer verilmeyen alt grup kelimelerine de yer verilmiştir.

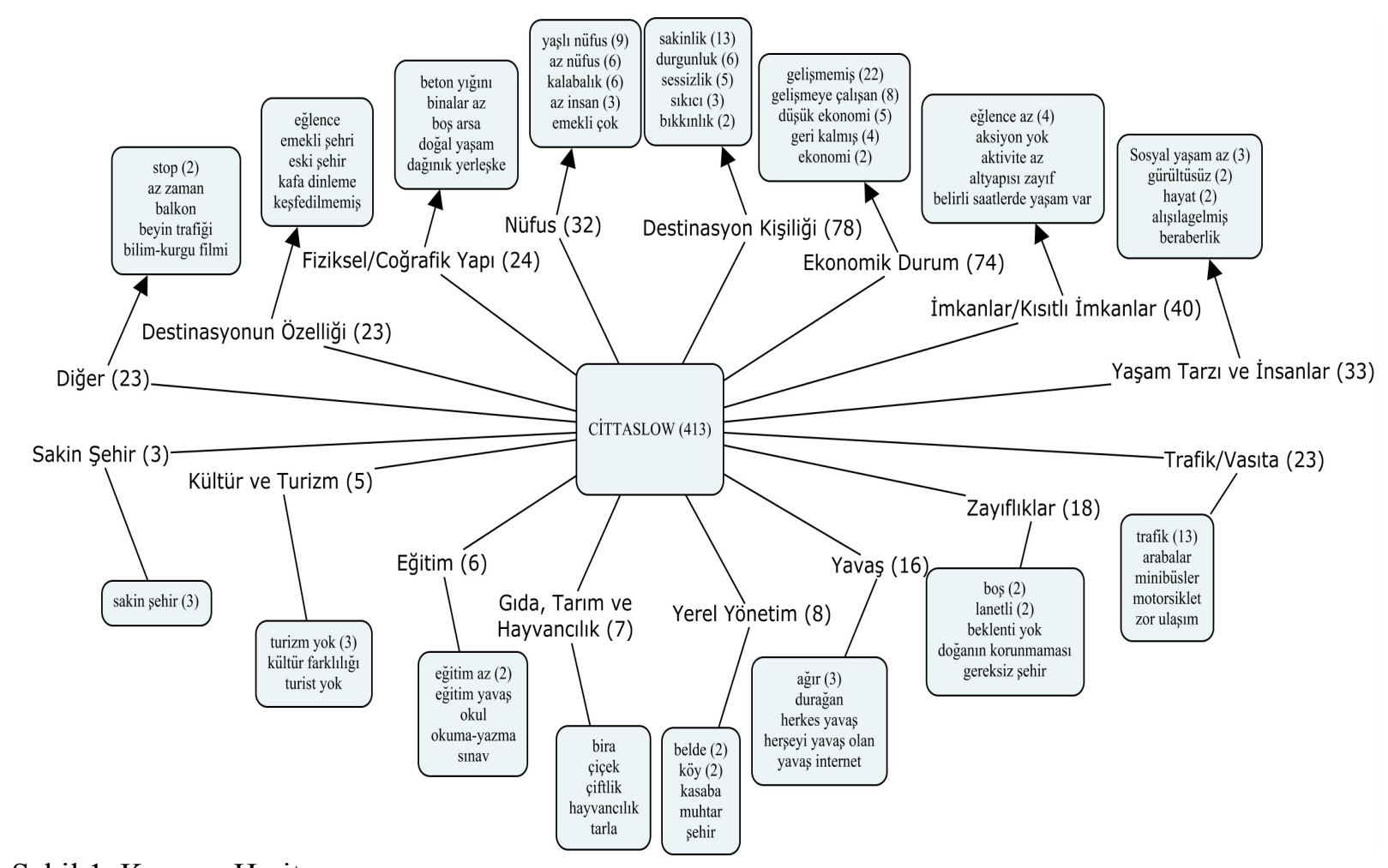

Şekil 1. Kavram Haritas 
Aşağıdaki tablolarda (Tablo 2 ve 3 ) ise kelime ilişkilendirme testinin ikinci bölümünde yer alan "ilgili cümle" kısmına yönelik öğrencilerin anahtar kavramla ilgili yapmış olduğu tanımlamalara yer verilmiştir. $\mathrm{Bu}$ tanımlamalar incelenerek kategorize edilmiştir. Kategorizasyon yapılırken Ercan, Taşdere ve Ercan'ın (2010) ve Yücel Güngör, Doğan ve Güngör'ün (2017) çalışmalarından yararlanılmıştır. Buna göre cümleler bilimsel bilgi içeren cümleler, bilimsel olmayan veya yüzeysel bilgi içeren cümleler ve kavram yanılgısı içeren cümleler şeklinde 3 kategoriden oluşmaktadır. Bilimsel bilgi içeren cümleler kategorisi, yapılan tanımlamanın anahtar kavramı tam anlamıla anlatan ve bilimsel içeriğe sahip olan cümlelerin yer aldığı kategoridir. Bilimsel olmayan veya yüzeysel bilgi içeren cümleler kategorisi, anahtar kavram ile ilgili yapılan tanımlamanın anahtar kavramla ilişkili kelimelerden oluşması fakat bilimsel içerikten uzak, kişiselleştirilmiş bir tanımın yapıldığı kategoridir. Kavram yanılgısı içeren cümleler ise anahtar kavramı açıklamayan ve anahtar kavramla ilişkilendirilemeyen tanımların yer aldığı kategoridir.

Tablo 2. Anahtar kavrama ilişkin öğrencilerin kurdukları ilgili cümlelerin frekans tablosu

\begin{tabular}{|c|c|c|c|c|}
\hline $\begin{array}{c}\text { Anahtar kav- } \\
\text { ram }\end{array}$ & $\begin{array}{c}\text { Bilimsel } \\
\text { bilgi içeren } \\
\text { cümle sayıs1 }\end{array}$ & $\begin{array}{c}\text { Bilimsel ol- } \\
\text { mayan veya } \\
\text { yüzeysel } \\
\text { bilgi içeren } \\
\text { cümle sayıs1 }\end{array}$ & $\begin{array}{c}\text { Kavram ya- } \\
\text { n1lgıs1 içeren } \\
\text { cümle sayıs1 }\end{array}$ & Boş \\
\hline $\begin{array}{l}\text { Cittaslow - } \\
\text { Yavaş Şehir }\end{array}$ & 0 & 12 & 45 & 1 \\
\hline
\end{tabular}

Tablo 2'ye bakıldığında anahtar kavram ile ilgili tanımlama yapan öğrencilerin hiçbirinin bilimsel bilgi içeren cümle kategorisi altında değerlendirilecek bir tanımlama yapmadığı görülmektedir. Öte yandan 12 öğrencinin yapmış olduğu tanımlama bilimsel olmayan veya yüzeysel bilgi içeren cümleler kategorisi altına girerken Ercan vd. (2010) ve Yücel Güngör vd. (2017) belirttiği gibi tanımlamaların çoğunluğu anahtar kavramı açıklamayan ve anahtar kavramla ilişkilendirilemeyen tanımlardan oluşmaktadır. 1 öğrenci ise bu bölümü boş bırakmıştır.

Tablo 3'te ise öğrencilerin yapmış olduğu tanımlamalardan oluşan örnek cümleler yer almaktadır.
Tablo 3. Kelime ilişkilendirme testinde elde edilen ilgili cümlelere ait bazı örnekler

\begin{tabular}{|c|c|}
\hline $\begin{array}{l}\text { Anahtar } \\
\text { Kavram }\end{array}$ & Bilimsel Bilgi İçeren Cümle Sayısı \\
\hline \multirow{13}{*}{$\begin{array}{l}\text { Cittaslow } \\
\text { - Yavaş } \\
\text { Şehir }\end{array}$} & --- \\
\hline & $\begin{array}{c}\text { Bilimsel Olmayan veya Yüzeysel Bilgi İçeren } \\
\text { Cümle Saylst }\end{array}$ \\
\hline & $\begin{array}{l}\text { İnsanların hızlı hayat, kalabalıktan kaçmak istediği } \\
\text { için bulunduğu yer veya yerlerdir. }\end{array}$ \\
\hline & Sakin ve telașesiz bir yaşantı. \\
\hline & Daha çok sessizliğin ve sakinliğin hakim olduğu \\
\hline & $\begin{array}{l}\text { Aynı statüdeki şehirler arasında son sıralarda tercih } \\
\text { edilen genelde ikinci planda kalan ama zaman içeri- } \\
\text { sinde farkına varılarak gelişime uğrayan gelişi- } \\
\text { minde bir sürat kazanan }\end{array}$ \\
\hline & İnsanların sakin ve acelesi olmadığ bir yer \\
\hline & Kavram Yanılgısı İçeren Cümle Sayısı \\
\hline & Kalabalık ihtiyar bir mutsuz hayat \\
\hline & Her konu hakkında yavaş arkadan gelen bir şehirdir \\
\hline & Yaşlı nüfus kalabalık ve eğlencesiz hayat \\
\hline & $\begin{array}{l}\text { Şehir yavaş olamaz çünkü bir yerden bir yere git- } \\
\text { mesi lazım ama şehirler bir yere gidemez }\end{array}$ \\
\hline & $\begin{array}{l}\text { Şehir 1şıklarının az olduğu yer benim için yavaş şe- } \\
\text { hirdir. Metropol olmayan birçok yeri yavaş şehir } \\
\text { olarak tanımlayabilirim. }\end{array}$ \\
\hline
\end{tabular}

Tablo 3'e bakıldığında 5 öğrencinin Cittaslow Yavaş Şehir'i insanların hızlı olduğu, kalabalıktan kaçanların geldiği, sessizlik ve sakinliğin hakim olduğu bir yerler olduğunu düşünmektedir. Öte yandan başka 5 öğrenci de mutsuz bir hayatın olduğu, yaşlı nüfusun yoğun olduğu 1şılkların az olduğu ve metropol olmayan yerler olduğu yanılgisına düşmüştür.

\section{Sonuc}

$\mathrm{Bu}$ araştırmada Adnan Menderes Üniversitesi Davutlar Meslek Yüksekokulu Turizm ve Otel İșletmeciliği Programı 2. sınıfında öğrenim gören 58 ön lisans öğrencisinin cittaslow - yavaş şehir kavramı ile ilişkili kavramlar hakkında bilişsel yapıları Kelime İlişkilendirme Testi (KITT) aracılığıyla ölçülmeye çalışılmıştır. Öğrencilere cittaslow - yavaş şehir kavramının kendileri için ne ifade ettiği sorulmuş ve buna karşıllk 295 cevap alınmıştır. Bu cevaplara bakıldığında öğrencilerin cittaslow - yavaş şehir anahtar kavramını en çok ilişkilendirdikleri yani frekans değeri en yüksek olan kelimelerin Gelişmemiş (22), Sakinlik (13), Trafik (13), Yaşlı Nüfus (9), Gelişmeye Çalışan (8), Durgunluk (6), Az Nüfus (6), Kalabalık (6) ve Düşük Ekonomi (5) olduğu görülmüştür. Cittaslow - yavaş şehir kavramını destinasyon bazında sakin ve durgun olarak nitelendirmektedir. Ekonomik anlamda ise ekonomisinin kötü olduğunu, işsizliğin olduğunu, gelişmeye çalışt1ğını belirtmektedirler. Yaşayan insan sayısı açısından 
ise kalabalık ve yaşlı nüfusun yoğun olduğu sonucu ç1karılmaktadır. Öğrencilere gore trafiğin de yoğun olduğu sonucuna ulaşılmaktadır. Buna göre cittaslow yavaş şehir kavramının her ne kadar gidilip görülmese de öğrenci algısında genel anlamda olumsuz bir çağrışım yaptı̆̆ 1 sonucuna varılmaktadır. Cittaslow - yavaş şehir hakkında yapılan tanımlamalara bakıldığında öğrencilerin bilimsel bilgi içeren tanımlama yapmadıkları, kavram hakkında bilgi veren kişiselleştirilmiş tanımlamaların yanında Ercan vd. (2010) ve Güngör vd. (2017) çalışmalarında da belirttikleri gibi kavram yanılgısının çoğunlukta olduğu tanımlamalar tespit edilmiştir. Öğrencilerin bir kısmı cittaslow - yavaş şehir kavramını bilim kurgu filmi, beyin trafiği, balkon, kaos kargaşa ve ölme riski gibi kelimelerle ilişkilendirmişlerdir. $\mathrm{Bu}$ durum öğrencilerin cittaslow - yavaş şehir kavramını algılayamadıkları ya da bu kavram hakkında bilgi sahibi olmadıklarını göstermektedir.

Güncel konulardan biri olan cittaslow - yavaş şehir hakkında öğrencilerin bilgi ihtiyacının giderilmesi konusunda öğretim programlarında güncelleme yapı1ması ya da turizm sektöründeki yenilikleri konu alan derslerin eklenmesi önerilmektedir. Cittaslow - yavaş şehir hareketinin katma değerinin yüksek olduğu düşünüldüğünde turizm sektörünün gelişmesine katk1 sağlayacak öğrencilere yönelik teknik geziler düzenlenerek öğrencilerin bu destinasyonlara yönelik bilgi düzeyleri arttırılmalı ve farkındalık yaratılmalıdır. Aynı şekilde cittaslow - yavaş şehir felsefesinin yeterince anlaşılması için gerekli tanıtımların, broşürlerin ve bilgilendirmenin bu destinasyonu pazarlama görevini üstlenen kişi ve kurum ve kuruluşlar tarafından yapılması önerilmektedir. Böylelikle yukarıda belirtilen cittaslow - yavaş şehir kavramının yapmış olduğu olumsuz çağrışımının olumluya çevrilmesi de mümkün hale geleceği düşünülmektedir. Cittaslow - yavaş şehir ile ilgili yapılan bu çalışmanın sadece ön test niteliği taş1ması nedeniyle benzer çalışma yapacak araştırmacılara ön test - son test yaparak karşılaştırma yapmaları önerilmektedir. Bu araştırmada sadece Turizm ve Otel İşletmeciliği Programı 2. sınıf öğrencilerinin cittaslow yavaş şehir hakkındaki bilişsel algıları ölçülmeye çal1şılmıştır. Diğer program öğrencilerini de içine alan bir ya da farklı anahtar kavramların kullanıldığı çalışmalar yapılabilir.

$\mathrm{Bu}$ araştırmanın sadece Turizm ve Otel İşletmeciliği Programı öğrencileri üzerine yapılması ve öğrencilerin Kelime İlişkilendirme Testini yaparken anahtar kavramın ne ifade ettiği ile ilgili boşlukların tamamını doldurmamaları bu araștırmanın kısıtlarındandır.

\section{Kaynakça}

Acuner, E.(2014). Çamlıhemşin için Cittaslow Model Önerisi: Karşılaştırmalı Bir Analiz (Doktora Tezi), Gazi Üniversitesi.
Altıntaş, S., Göçen Kabaran, G. ve Kabaran, H. (2018). Öğretmen Adaylarının Eğitim Programı Kavramına İlişkin Bilişsel Yapılarının Kelime İlişkilendirme Testi İle Belirlenmesi, Turkish Studies, 13(4), 1397-1411.

Başar, M. ve Göncü, A. (2018). Sinıf Öğretmenlerinin Öğgrenme Güçlüğüyle İlgili Kavram Yanılgılarının Giderilmesi ve Öğretmen Görüşlerinin Değerlendirilmesi, $\mathrm{Ha}$ cettepe Üniversitesi Eğitim Fakültesi Dergisi, 33(1), 185-206.

Cittaslow (2018) Association. Retrieved from: http://www.cittaslow.org/sites/default/files/content/page/files/246/cittaslow_list_july_2018.pdf, (14.08.2018).

Çeliköz, M. ve Erişen, Y. (2017). EPÖ Alanında Görev Yapan Eğitim Bilimcilerin Yapılandırmacılıkla İlgili Görüşleri: Bir Karma Yöntem Araştırması, Eğitim ve Öğretim Araşstırmaları Dergisi, 6(2), 286-304.

Doğan, S., Yücel Güngör, M. ve Güngör, O. (2018). Turizm Meslek Yüksekokulu Öğrencilerinin Sosyal Medyaya Yönelik Bilişsel Yapılarının Kelime İlişkilendirme Testi Aracılığıyla İncelenmesi, Turizm Akademik Dergisi, 5(1), 166-176.

Ekici, G., Gökmen, A. ve Kurt, H. (2014). Öğretmen Adaylarının "Bilgisayar" Kavramı Konusundaki Bilişsel Yapılarının Belirlenmesi, Gazi Üniversitesi Eğitim Fakültesi Dergisi (GEFAD), 34(3), 357-401.

Firat, A. ve Aydın, A. E. (2016). Hedonik ve Faydacı Alışveriş Davranışı Üzerine Bir Araştırma, Uluslararası Sosyal Araştırmalar Dergisi, 9(43), 1840-1846.

Gülertekin Genç, S., Genç, V. ve Gümüş, M. (2016). Otel İşletmelerinde Duygusal Zekanın İş Stresi ve İş Yaşam Dengesi Üzerindeki Etkisi, Batman Üniversitesi Yaşam Bilimleri Dergisi, 6(2/1), 97-112.

Gündoğan, A ve Gültekin, A. (2018). İlkokul 3. Sınıf Öğrencilerinin Hayat Bilgisi Dersi "Okul Heyecanım” Temasındaki Kavramlara İlişsin Bilişsel Yapıları, Elektronik Sosyal Bilimler Dergisi, 17(65), 233-247.

Keleş, Ö., Gilbertson, K.L. ve Uzun, N. (2016). Cognitive Structures of University Students about Environmental Education, Climate Change and Consumption Concepts, Asia-Pacific Forum on Science Learning and Teaching, 17(2), 1-17.

Keskin, E. ve Örgün, E. (2015). Kelime İlişkilendirme Testi Aracılığıyla Sürdürülebilir Turizm Olgusunun Kavramsal Analizi: Ürgüp Örneği, Journal of Tourism and Gastronomy Studies, 3(1), 30-40.

Keskin, E., Örgün, E. ve Akbulut, B.A. (2017). Gastronomi Kavramının Kelime İlişkilendirme Testi Aracıllığıla 
Analizi, Journal of Tourism and Gastronomy Studies, 5(3), 255-267.

Knox, P. L. (2007). Creating Ordinary Places: Slow Cities in a Fast World, Journal of Urban Design, 10(1), 1-11.

Önal, N. (2017). Bilişim Teknolojileri Öğretmen Adaylarının Bölümlerine Yönelik Bilişsel Algılarının KİT Aracılığıyla İncelenmesi, Ahi Evran Üniversitesi Kırşehir Ĕgitim Fakültesi Dergisi (KEFAD), 18(2), 255-272.

Önel, A. ve Yüce, A. (2016). Determining The Cognitive Structures of Science Teacher Candidates On "Evolution" Through Word Association Test, Journal of Educational Science Research, 6(1), 23-39.

Radstrom, S. (2011). A Place Sustaining Framework For Local Urban Identity: An Introduction and History Of Cittaslow, Italian Journal of Planning Practice, 1(1), 90113.

Slow Food (2018). Our Philosophy, https://www.slowfood.com/about-us/our-philosophy/, (14.08.2018).
Su, W. S., Huang, C. H., Hsu, C. C. \& Chang, L. F. (2017). Cittaslow: A New Pattern Of Sustainable Tourism Development in Taiwan. The International Journal of Organizational Innovation, 9(4), 90-103.

UNWTO (2017). Tourism Highlights 2017 Edition, Madrid: UNWTO.

Yurtseven, H. R. ve Kaya, O. (2011). Slow tourists: a comparative research based on cittaslow principles. American International Journal of Contemporary Research, 1(2), 91-98.

Yücel Güngör, M., Doğan, S. ve Güngör, O. (2017). Aşçılık Programı Öğrencilerinin Sosyal Medyaya Yönelik Bilişsel Yapılarının Kelime İlişkilendirme Testi Aracılığıyla İncelenmesi, Journal of Tourism and Gastronomy Studies, 5(2), 206-218.

Zawadzka, A. K. (2017). Making Small Towns Visible in Europe: The Case of Cittaslow Network - The Strategy Based on Sustainable Development. Transylvanian Review of Administrative Sciences, Special Issue, 90-106. 


\section{Extended abstract in English}

The Slow City, which is an alternative to the crowded, large and noisy cities of the 21st century, consists of a combination of the Italian Citta (City) and Slow (Slow) English (Acuner, 2014: 1). Cittaslow - The Slow City was founded in 1999 by Paolo Saturnini (Mayor of Greve in Chianti) together with the mayors of Orvieto (Stefano Cimicchi), Bra (Francesca Guida), Positano (Domenico Marrone) and Carlo Petrini (Chief executive of Slow Food), 2011: 91). Cittaslow - The Slow City brings together the cities whose population are less than 50,000, and have specific environmental, archaeological or cultural values (Zawadzka, 2017: 94). Cittaslow - Slow City which is a network of international small cities, was established in Italy to adapt the slow food philosophy (Slow Food, 2018) to urban design and planning with principles of good, clean and fair food (Yurtseven and Kaya, 2011: 91). By using technology, it commits to create healthier environments, to raise awareness of the value of slow life and to find administrative solutions for better quality of life (Knox, 2007: 7). Today there are 252 Slow Cities in 30 countries worldwide. While Italy which has 84 of these 252 cities takes first place in this context, Turkey which has 15 Slow City takes 4th place (Cittaslow, 2018). While Cittaslow - Slow City movement is based on the concept of slow food, it is being developed further by reaching out to cities and tourism. In recent years, the concept of slow travel has also become a concept about Cittaslow - Slow City (Su, et al., 2017: 92). In order to determine the cognitive structures of the Slow City concept, the word association test was used as a data collection tool. The Word Association Test (WAT) reveals the links between the concepts in the cognitive structure of the students and determines whether the relationship between the concepts in long-term memory is sufficient or meaningful or not. In this technique, within 30 to $45 \mathrm{sec}-$ onds students are asked to write the words that key concepts associate in their minds (Altıntaş et al., 2018:1403; Başar and Göncü, 2018:189; Gündoğan and Gültekin, 2018:236; Doğan et al., 2018:169; Yücel Güngör et al., 2017:210; Önal, 2017:257; Önel and Yüce, 2016:26; Keleş et al., 2016:6; Keskin and Örgün, 2015:32; Ekici et al., 2014:362). The Word Association Test which is used in social sciences, especially in educational sciences in recent years is being used in academic research in tourism field too (Doğan et al., 2018; Yücel Güngör et al., 2017; Kesin et al., 2017; Keskin and Örgün, 2015). 60 students studying in the 2nd year of Tourism Management Program in Adnan Menderes University Davutlar Vocational
School has been determined as a study group. The research was carried out with 58 students in the course time to collect the data. The students were asked what the cittaslow - slow city concept meant for them and 295 responses were obtained. When these answers have been looked at, it has been seen that students mostly associated the concept of cittaslow - slow city key with the highest frequency value of the words: Undeveloped (22), Calmness (13), Traffic (13), Elder Population (9), Struggling to Develop (8), Recession (6), Low Population (6), Crowd (6) and Low Economy (5). They describe the Cittaslow - slow city concept as calm and quite in the context of destination. In terms of economic, they state that their economy is bad, there is unemployment and they try to develop. In terms of the number of people living on the other hand, it is concluded that elderly population is intense. According to the students, it is concluded that the traffic is also intense. According to this, it is concluded that the concept of cittaslow - slow city has a negative connotation in student perception, although not have gone and have seen there. When looked at the definitions made about the Cittaslow -slow city, it has been detected that the students did not make definition including scientific knowledge, and the definitions were detected majority of which are misconception besides the personalized descriptions that give information about the concept, as Ercan et al. (2010) and Güngör et al. (2017) stated. Some of the students linked the concept of cittaslow - slow city with words such as science fiction film, brain traffic, balcony, chaos turmoil and risk of dying. This situation has shown that the students could not perceive or understand the concept of cittaslow - slow city. To meet the information needs of the students about Cittaslow - the slow city which is one of the current issues, it is recommended to update the curriculum or to add courses related to the innovations in the tourism sector. Considering that the added value of Cittaslow- the slow city movement is high, technical trips should be organized for the students who will contribute to the development of the tourism sector and students' level of knowledge towards these destinations should be increased and awareness should be raised. In the same way, it is recommended that the promotions, brochures and information required to understand the Cittaslow - slow city philosophy enough, should be done by the persons and institutions and organizations that carry out this marketing task. Thus, it is thought that it will be possible to turn the negative association of the Cittaslow - slow city concept into a positive one. 